\title{
Menstimulasi Para Ibu Anggota Kelompok Pengajian Menjadi Startup
}

\author{
Stimulating The Mothers Of The Study Group Members To Become Startups \\ Shofia Amin ${ }^{* 1}$, Rike Setiawati ${ }^{2}$, Fitri Widiastuti $^{3}$, Mulyadi Raf ${ }^{4}$, Asep Machpudin ${ }^{5}$ \\ 1,2,3,4,5 Fakultas Ekonomi dan Bisnis Universitas Jambi, Jambi, Indonesia \\ *Penulis Korespondensi \\ 1shofiaamin@,unja.ac.id
}

Riwayat Artikel: Dikirim 30 Juni 2021; Diterima 14 September 2021; Diterbitkan 30 November 2021

\begin{abstract}
Abstrak
Menjadi startup bagi para ibu anggota kelompok pengajian merupakan salah satu upaya dalam meningkatkan pendapatan keluarga. Akan tetapi, jika kurang memiliki keberanian untuk memulai suatu usaha, semua keinginan hanya akan menjadi sebuah impian yang tak akan terwujud. Kegiatan pengabdian ini bertujuan untuk menstimulasi keberanian dan merubah mindset ibu-ibu kelompok pengajian Raudhatul Jannah Desa Koto Rendah Kecamatan Siulak Kabupaten Kerinci Jambi untuk mengembangkan potensi dirinya dari sebagai seorang ibu rumah tangga yang sehari hari memiliki kegiatan berkebun, menjadi startup dengan bersinergi dengan para anggota kelompoknya. Melalui metode ceramah dan tanya jawab, materi kegiatan tentang cara memulai bisnis startup, faktor penentu keberhasilan startup, peran teknologi dalam bisnis dan membuka akses pemasaran berbasis online diberikan kepada mereka. Hasil yang dicapai dari kegiatan pengabdian ini adalah terbentuknya Kelompok Usaha Bersama (KUBE) yang terdiri dari kelompok usaha sejenis dan berkolaborasi dalam menjalankan usaha secara berkelompok.
\end{abstract}

Kata kunci: Startup, Ibu-ibu kelompok pengajian, Pemasaran online

\begin{abstract}
Becoming a startup for mothers who are members of the recitation group is an effort to increase family income. However, if we don't have the courage to start a business, all of our wishes will just become a dream that won't come true. This service activity aims to stimulate courage and change the mindset of the women of the Raudhatul Jannah recitation group, Koto Rendah Village, Siulak District, Kerinci Jambi Regency to develop her potential from being a housewife who has daily gardening activities, becoming a startup by synergizing with her group members. Through the counseling and discussion method, how to start a startup business, determinants of startup success, the role of technology in business and opening access to online-based sales are given to them. The result achieved is the formation of a Joint Business Group (KUBE) which consists of similar business groups and collaborates in running businesses in groups.
\end{abstract}

Keywords: Startup, Women recitation groups, Online marketing

\section{PENDAHULUAN}

Kabupaten Kerinci merupakan salah satu kabupaten di Provinsi Jambi, Indonesia yang ditetapkan sebagai kabupaten sejak awal berdirinya Provinsi Jambi. Pusat pemerintahan berada di Sungai Penuh dan memiliki luas wilayah $332.814 \mathrm{Ha}$, terdiri dari 16 Kecamatan dengan jumlah desa sebanyak 285 desa dan 2 kelurahan dengan 12 wilayah Kecamatan. Sebagai salah satu wilayah ujung Barat Provinsi Jambi yang berbatasan langsung dengan Provinsi
Sumatera Barat dan Provinsi Bengkulu, Kabupaten Kerinci menjadi wilayah strategis yang dilalui jalan utama Jambi-Sumatera Barat-Bengkulu.

Dari survey awal tim ke lokasi pengabdian, terbukti Kerinci memiliki potensi besar di bidang pariwisata karena keindahan alamnya yang asri. Karunia ini memberikan sinyal keterbukaan peluang bisnis bagi masyarakat Kerinci karena ramai dikunjungi para wisatawan domestik maupun mancanegara ataupun sebagai lokasi shooting film dan program wisata di televisi. 
Salah satu desa yang menarik untuk dikunjungi adalah Desa Koto Rendah Kecamatan Siulak yang berlokasi sekitar 15 $\mathrm{km}$ dari Kota Sungai Penuh. Sejarah terbentuknya Desa Koto Rendah diperkirakan dimulai dari Abad $17 \mathrm{M}$. Koto Rendah berasal dari kata "kota merendah". Menurut Tambo Adat Tigo Luhah Tanah Sekudung (tokoh adat setempat), sebelum Depati Mangku Bumi bersembah menghadap raja Jambi di Muara Masumai, beliau bertapa di wilayah Air Manimbak berbatasan dengan Solok Selatan sekarang. Di lokasi tersebut beliau mendapatkan seekor siamang berkulit Putih yang mengikuti beliau dari atas pohon hingga ke Siulak Panjang. Saat beliau berhenti di sebuah kawasan utara Siulak Panjang, Siamang tersebut turun dari pohon dan merendah. Lokasi tempat turunnya siamang putih tersebut sampai sekarang dinamakan sebagai Koto Rendah.

Gambar 1:

Situasi Desa Koto Rendah

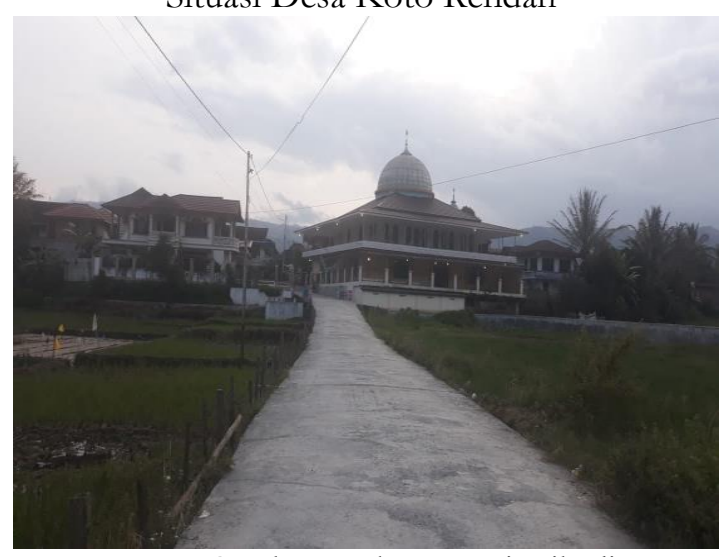

Sumber: Dokumentasi pribadi

Aktifitas sehari-hari masyarakat Desa Koto Rendah khususnya ibu-ibu sebagian besar bertani dan berkebun. Kegiatan sampingan mereka adalah menghadiri kelompok pengajian yang dilakukan setiap 1 kali dalam satu minggu. Salah satu kelompok pengajian yang menjadi mitra tim PPM adalah "Kelompok Pengajian Raudhatul Jannah". Berdasarkan survey dan wawancara awal dengan ketua kelompok pengajian, terindikasi bahwa para anggota yang terdiri dari ibu-ibu rumah tangga kebanyakan ikut memasarkan produk hasil tani dan kebunnya ke pasar yang diadakan satu sekali dalam sepekan. Apabila barang yang dijual tidak laku atau tidak habis, maka mereka akan menjual barang hasil kebunnya dengan sistem jual borong dengan harga yang sangat murah. Kondisi ini merupakan kerugian bagi mereka. Apalagi produk yang dihasilkan berupa kentang dan sayur mayur yang merupakan barang yang mudah rusak dan tidak bertahan lama.

Permasalahan lain yang mereka hadapi saat ini adalah kurangnya kemampuan untuk memperoleh akses informasi dalam mengembangkan potensi yang dimiliki. Mereka juga memiliki ketidakberanian untuk memulai usaha, ketidaktahuan cara mendapatkan bantuan dana serta rasa takut dan ragu jikalau usaha tersebut tidak berkembang/gagal. Keraguan ini yang menjadikan para ibu-ibu menunda merubah cara dan hanya menjual secara tradisional di pasar seminggu sekali. Padahal peluang bisnis selalu ada bagi yang kreatif dan inovatif. Apalagi daerah Kerinci merupakan salah satu kawasan pariwisata Jambi, dengan membuka usaha home industri dari hasil kebun sendiri, tentu merupakan peluang yang tidak dapat diabaikan. Home industri memiliki keungulan karena tidak memerlukan modal yang besar namun dapat memberikan tambahan penghasilan tanpa harus meninggalkan rumah (Hamdi \& Yadewani, 2019).

Kelompok Pengajian Raudhatul Jannah yang beranggotakan para ibu dengan berbagai keterampilan akan menjadi suatu sinergi jika diberdayakan membentuk startup. Dengan bersinergi akan saling berbagi sumber daya yang dimiliki sehingga akan tercipta efisiensi, kreativitas, inovasi dan saling berbagi ilmu sebagai faktor penentu kesuksesan startup (Hardiansyah \& Tricahyono, 2019). Startup itu sendiri adalah bisnis baru yang dimulai oleh pengusaha dengan menggabungkan ide dan sumber daya bisnis (Kim, Kim, \& Jeon, 2018). Kehadiran startup akan berkontribusi terhadap perkembangan industri kreatif di Tanah Air, mengatasi persoalan yang dihadapi UKM seperti pemasaran, promosi, manajerial, informasi, SDM, teknologi, 
desain, jejaring (networking), dan pembiyaan yang sebagian besar bergerak pada industri kreatif. Startup juga berkontribusi dalam mengurangi tingkat kemiskinan dan tingkat pengangguran (Syauqi, 2016). Untuk mem[ermudah dan memperluas jangkauan customer, maka startup dapat menggunakan media sosial dalam melakukan pengenalan produk (Lutfiani, Rahardja, \& Manik, 2020).

Untuk memulai usaha baru, diperlukan keberanian dan kreativitas.Secara konseptual ketidakberanian biasanya timbul karena calon wirausaha belum memiliki informasi terkait bisnis yang akan dijalankan, merasa tidak berbakat, kurang optimis, tidak memiliki pengalaman berusaha yang mana hal ini menjadi modal dasar dalam menjalankan usaha. Sebuah studi kualitatif yang dilakukan oleh Amin, Widiastuti dan Fitriaty (2019) terhadap empat ibu-ibu entrepreneur sektor kuliner di Kota Jambi menyimpulkan bahwa untuk berhasil dalam usaha bisnis maka diperlukan karakter pribadi, dukungan pasangan, keluarga dan pemerintah, komunikasi dangan organisasi professional, keterampilan manajerial, kesetiaan karyawan, cepat tanggap dalam menangani keluhan pelanggan dan bersikap dermawan. Dengan berkelompok akan menimbulkan keberanian untuk membentuk usaha baru.

Bertolak dari fenomena inilah maka dirasa perlu untuk melakukan kegiatan pengabdian kepada masyarakat dalam bentuk penyuluhan tentang bagaimana menjadi startup untuk meningkatkan pendapatan keluarga pada kelompok ibu-ibu di Desa Koto Rendah Kecamatan Siulak Kabupaten Kerinci. Penyuluhan ini diselenggarakan dengan tujuan membantu masyarakat memperoleh informasi dan motivasi agar ada peningkatan kemampuan dan rasa percaya diri untuk menggunakan potensi yang dimiliki dalam menjalankan usaha. Sangat disayangkan, mereka memiliki potensi namun tidak dimanfaatkan.

\section{METODE}

\section{Metode Pelaksanaan}

Tim Pengabdian Pada Masyarakat (PPM) memilih metode penyuluhan dan pendampingan dalam memberikan pemahaman makna dan peran startup, cara memulai membentuk startup untuk menstimulasi para anggota menjadi startup dengan membentuk kelompok usaha bersama (KUBE).

\section{Langkah - Langkah Kegiatan}

Untuk mengatasi permasalahan mitra, tim pelaksana kegiatan menyusun perencanaan langkah - langkah pelaksanaan kegiatan yang akan dilakukan. Secara keseluruhan perencanaan kegiatan meliputi:

a) Persiapan, langkah-langkah yang akan dilakukan:

1. Tim melakukan rapat internal antar anggota untuk mendiskusikan dan memutuskan teknis pelaksanaan kegiatan dan pembagian tugas masing-masing.

2. Tim menjalin komunikasi dengan mitra untuk menjelaskan maksud dan tujuan kegiatan sehingga meminimalisir perbedaan perspektif antara kedua belah pihak. Hal ini penting agar tim pelaksana dapat menggali informasi-informasi dan merumuskan permasalahan mitra secara faktual. Selanjutnya, hubungan antara tim pelaksana dan mitra dibangun berdasarkan pendekatan kemitraan, dimana mitra memiliki permasalahan yang harus diatasi sementara tim pelaksana memberikan tawaran solusi terhadap permasalahan tersebut. Disepakati juga tentang waktu dan tempat pelaksanaan kegiatan.

3. Tim pelaksana melakukan koordinasi dengan perangkat desa. Hal ini dilakukan untuk memberitahukan kepada perangkat desa setempat bahwa ada kegiatan yang dilaksanakan di daerah lokasi tempat tinggal mitra. Selain itu beberapa dokumen administrasi seperti surat 
menyurat juga dipersiapkan. Disepakati kepala Desa atau yang mewakili akan hadir pada hari pelaksanaan.

4. Tim pelaksana juga mempersiapkan administrasi terkait dengan perizinan dan surat tugas melalui Fakultas dan Lembaga Pengabdian Kepada Masyarakat Universitas Jambi. Tim juga mempersiapkan daftar hadir peserta dan spanduk kegiatan sebagai bukti kegiatan telah dilaksanakan.

5. Mempersiapkan mahasiswa untuk membantu pelaksanaan kegiatan. Mahasiswa yang akan dilibatkan berjumlah 2 orang yaitu mahasiswa Fakultas Ekonomi dan Bisnis Universitas Jambi. Mahasiswa akan dilibatkan dalam pemantauan perkembangan mitra dan dokumentasi kegiatan.

b) Pelaksanaan. Pada kegiatan pelaksanaan ada beberapa hal langkah-langkah solusi yang direncanakan akan dilakukan yaitu:

1. Memberikan materi tentang pemahaman makna dan peran startup, faktor penentu keberhasilan startup, cara memulai membentuk startup dan akses pemasaran online

2. Diskusi dan tanya jawab tentang permasalahan yang mereka hadapi.

3. Pendampingan dalam membentuk kelompok usaha bersama (KUBE) dan di dalam KUBE tersebut di bentuk juga struktur organisasi yang baik.

c) Evaluasi

1. Evaluasi mitra tentang kemampuan dalam inovasi dan pengembangan produk agar dapat meningkatkan kualitas produk dan daya tahan produk.

2. Evaluasi jenis model pemasaran yang akan dijalankan oleh mitra.

Berikut gambar prosedur kegiatan yang dilakukan:
Gambar 2:

Prosedur Kerja

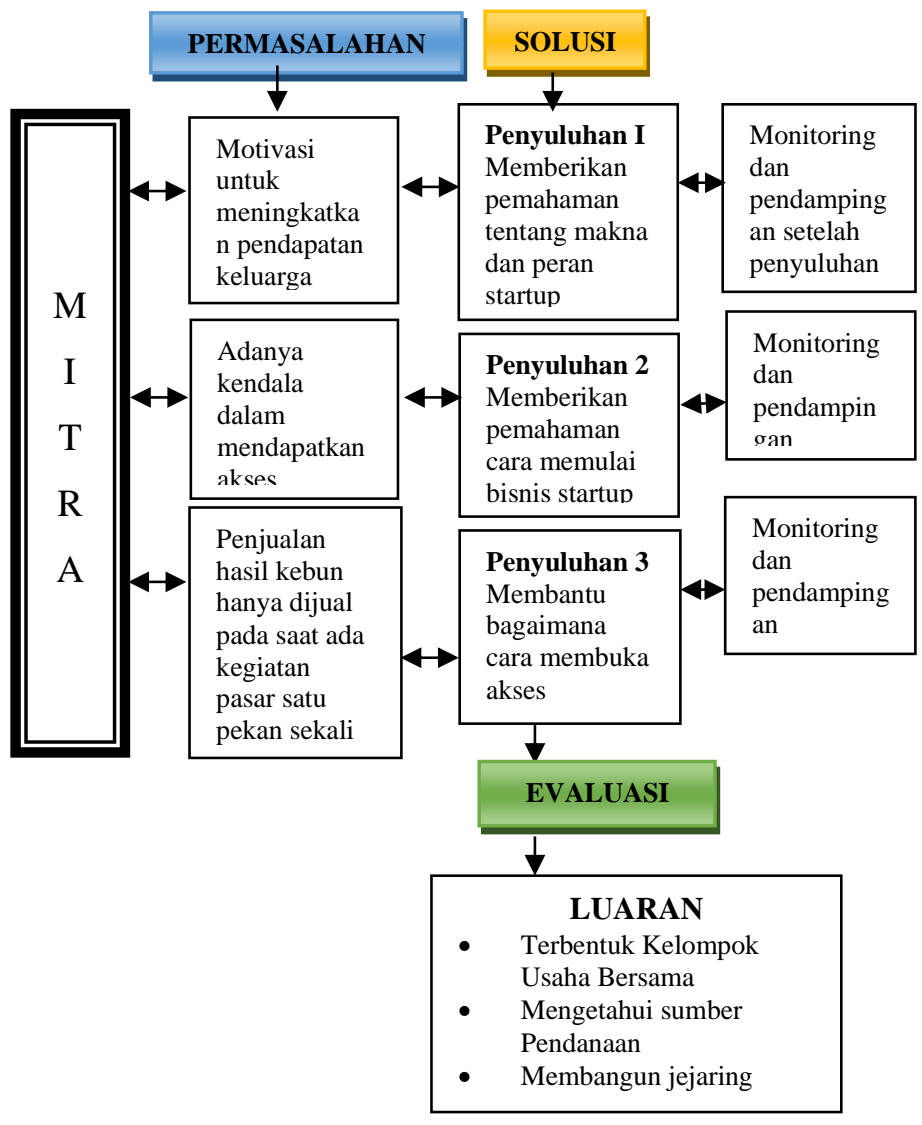

HASIL DAN PEMBAHASAN

\section{Pelaksanaan Kegiatan PPM}

Sehari sebelum keberangkatan dari Jambi menuju lokasi di Kabupaten Kerinci, Tim pelaksana melakukan konfirmasi ulang kepada mitra dan perangkat Desa via telephon untuk memastikan kesiapan mereka menerina Tim pelaksana kegiatan. Tim pelaksana juga melakukan melakukan rapat internal akhir untuk memeriksa kembali persiapan dan perlengkapan yang harus dibawa.

Dengan menyewa mobil, tim sampai di lokasi pada jam 09.00 pagi wib. Setelah saling berkenalan antar Tim pelaksana dan mitra, acara dimulai pada pada jam 10.00 wib Turut hadir pada acara tersebut para perangkat desa yang terdiri dari sekretaris desa dan 2 orang stafnya. Para pemateri terdiri dari para anggota tim pelaksana masing-masing menyampaikan materi sesuai kompetensinya dari perspektif kewirausahaan, manajemen 
sumber daya manusia, manajemen pemasaran dan manajemen keuangan. Sekretaris Desa yang hadir juga diberikan kesempatan untuk memberikan pengarahan dalam rangka memotivasi para ibu anggota kelompok mitra.

Mitra terlihat antusias mendengarkan, terbukti dari banyaknya pertanyaan yang diajukan. Tim pelaksana merasa bersyukur karena semua anggota mitra dapat berbahasa Indonesia dengan baik meski berdiam di Kabupaten Kerinci yang memiliki bahasa daerah tersendiri. Diskusi dan tanya jawab berjalan lancer dan hangat dan acara berakhir dengan makan siang bersama di rumah kediaman ketua kelompok mitra. Setelah makan siang, dilanjutkan dengan photo bersama.

Gambar 3:

Tim PPM bersama Mitra dan Sekretaris Desa Koto Rendah

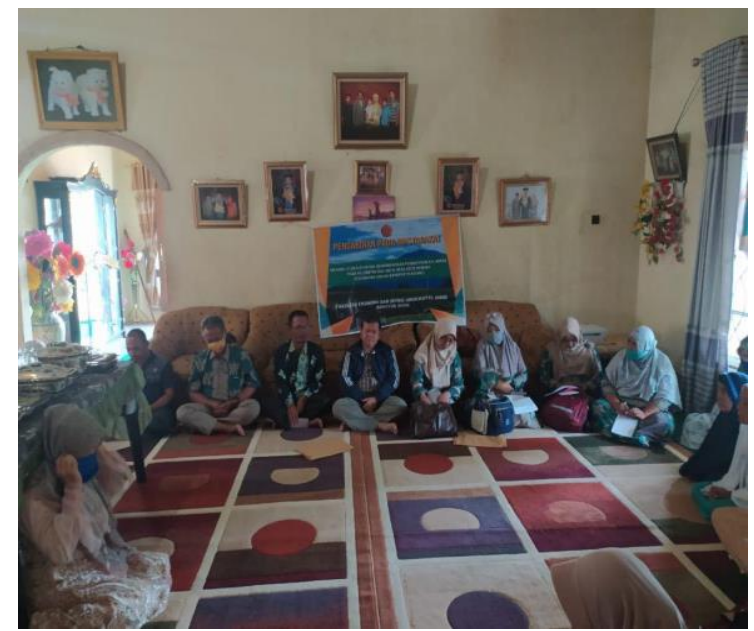

Sumber: Dokumentasi pribadi

\section{Hasil Kegiatan}

Dari hasil penyampaian materi dan tanya jawab, semakin diyakini bahwa permasalahan pertama yang dihadapi mitra adalah belum memahami makna dan peran startup sehingga belum ada keberanian untuk memulai usaha. Dengan merujuk kepada hasil penelitian Jaya Ferdiana dan Fauziati (2017), startup didefinisikan sebagai usaha rintisan yang dirancang untuk menemukan model bisnis yang tepat untuk perusahaannya agar dapat bertahan di tengan ketidakpastian yang ekstrem. Dengan bahasa sederhana dapat dikatakan startup adalah usaha rintisan yang baru berdiri. Untuk memulai usaha ini disarankan lebih baik dilakukan secara berkelompok agar bisa berbagi ilmu, pengalaman, keterampilan dan modal finansial.

Faktor penentu kebehasilan startup seperti yang dikemukakan oleh Bill Gross berdasarkan hasil penelitiannya terhadap 200 perusahaan, disimpulkan sebagai berikut: (1) timing (waktu yang tepat) dengan kontribusi $42 \%$, (2) Tim/Eksekusi, 32\%, (3) ide, 28\%, (4) model bisnis, $24 \%$ dan pendanaan $14 \%$ (Dessi, 2020). Peneliti lainnya (Br Sitepu, 2017) menemukan bahwa keberhasilan startup dipengaruhi dominan oleh variabel human relation dibandingkan dengan kompetensi teknik, finansial dan marketing. Human relation yang diaksud adalah kemampuan berkomunikasi dan membangun hubungan baik dengan karyawan, rekan kerja, pelanggan maupun supplier. Dari dua hasil penelitian tersebut, dapat menguatkan hati mitra, bahwa untuk menjadi startup, aspek finansial dalam bentuk modal uang bukanlah hal yang utama. Dengan demikian, mitra dapat memulai membentuk startup dengan bermodalkan kekompakan tim dan pemilihan model bisnis home industri sesuai dengan masa pandemi covid-19.

Dari hasil diskusi, setelah mendengarkan materi, mitra mengemukakan niatnya untuk berwirausaha. Hasil ini sangat mengembirakan. Nugraha dan Wahyuhastuti (2017) menjelaskan bahwa dalam memulai sebuah start-up bisnis harus dimulai dari niat calon pelaku usahanya. niat berwirausaha merupakan motivasi untuk membuat perencanaan secara sadar yang bertujuan untuk mendirikan sebuah bisnis. Dengan niat yang kuat, akan mendorong mereka untuk berperilaku mewujudkan keinginannya. Adapun ide bisnis pada tahap awal yang dapat segera diwujudkan adalah pembuatan kue tradisional berbahan baku lokal (kentang dan sayuran) dan penjualan sayuran dengan sistim online. Pemasaran online saat ini dapat dilakukan dengan teknologi menggunakan smartphone dan aplikasi pendukungnya. Dengan demikian, mitra tidak pasif hanya 
menunggu pembeli datang, tetapi proaktif dengan mempromosikan produknya melalui medsos dan sistem penjualan antar alamat. Selain itu dengan pemasaran online, mitra tidak memerlukan banyak tempat. Mereka cukup memajang display foto dari produk yang ditawarkan dan menjangkau calon pembeli secara meluas.

Permasalahan kedua yang mereka hadapi adalah masih rendahnya pengetahuan untuk memperoleh atau mendapatkan akses informasi secara online bagaimana cara memulai usaha. Di dalam pelatihan dan penyuluhan, tim membantu mitra bagaimana cara menemukan ide bisnis, memperoleh sumber dana untuk membuka usaha, serta membentuk networking (jejaring). Sebuah disain startup didesain dengan menciptakan desain baru secara konstan, menghasilkan produk baru dengan mengaplikasikan ide baru dan menyadari keinginan pasar dan perubahan lingkungan. Tim juga menjelaskan pentingnya mengatur dan mencatat keuangan secara sederhana. Secara rinci beberapa hasil yang telah dicapai dalam pelaksanaan kegiatan PPM, adalah sebagai berikut:

1. Tim juga memberikan penjelasan tentang merintis sebuah startup adalah perkara mudah. Siapa saja bisa mulai membangun startup digital. Akan tetapi, hal yang sulit justru adalah menjaga startup itu tetap eksis dan terus berkembang. Karenanya diperlukan kekompakan tim untuk menghasilkan sinergi dengan saling berbagi pengetahuan, pengalaman dan pendanaan.

2. Bagaimana membangun jejaring untuk menjalin partnership dengan lembaga terkait yang akan membantu mitra dalam menjalankan usaha juga disampaikan.

3. Terakhir, dukungan dari aparat Desa semakin menguatkan tekad para ibu Kelompok Pengajian untuk segera membentuk Kelompok Usaha Bersama.
Gambar 4:

Tim PPM bersama Mitra dan aparat Desa

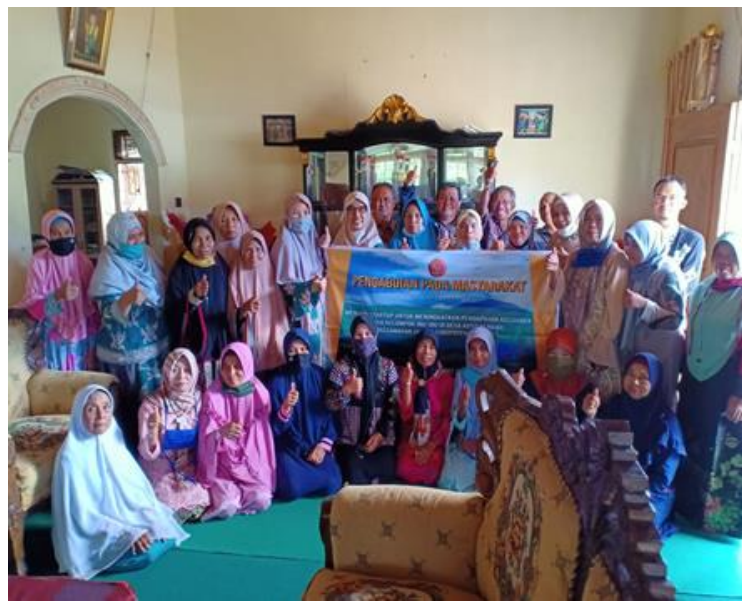

Sumber: Dokumentasi pribadi

\section{KESIMPULAN}

Kegiatan pengabdian di Desa Koto Rendah Kecamatan Siulak Kabupaten Kerinci Provinsi Jambi dengan mitra para ibu Kelompok Pengajian Raudhatul Jannah telah dilaksanakan dengan dihadiri aparat desa. Respon mitra sangat antusias. Beberapa permasalahan dan solusi telah diberikan dengan hasil nyata terbentuknya Kelompok Usaha Bersama (KUBE) dengan produk awal adalah pembuatan kue tradisional berbahan baku lokal dari hasil kebun sendiri, yaitu kentang dan sayuran. Memang kegiatan dan usaha ini tidak bisa sekali jadi. Perlu pembinaan dan pendampingan selanjutnya agar mereka menjadi startup yang tetap eksis dan berkembang.

Dari hasil pelaksanaan kegiatan yang telah dilakukan, disarankan perlu adanya kegiatan lanjutan untuk melakukan monitoring atas kegiatan pembentukan Kelompok Usaha Bersama (KUBE) yang telah mereka lakukan dalam rangka menjaga keberadaan, keberlangsungannya dan memberi solusi atas masalah yang mereka hadapi dalam usaha tersebut. Keterlibatan Pemerintah khususnya Dinas Pemberdayaan Masyarakat Desa terkait dukungan pendanaan dan legalisasi kelompok usaha mereka juga sangat diharapkan. 


\section{DAFTAR PUSTAKA}

Amin, S., Widiastuti, F., \& -, F. (2019). What the Meaning of Success in Female Entrepreneurs' Perceptions? An Interview-Based Study. International Journal of Human Resource Studies, 9(4), 133. https://doi.org/10.5296/ijhrs.v9i4.1526 0

Br Sitepu, S. N. (2017). Pengaruh Faktor Internal Terhadap Keberhasilan StartUp Bisnis Di Kota Surabaya. Jumal Manajemen Teori Dan Terapan | Journal of Theory and Applied Management, 10(1), 37. https://doi.org/10.20473/jmtt.v10i1.51 36

Dessi, C. (2020). 5 Top Indicators for Startup Success, According to this TED Talk. The biggest reason why startups succeed today. Inc.Com. Retrieved from https://www.inc.com/chris-dessi/thisted-talk-explains-the-5-reasons-whystartups-succeed.html

Hardiansyah, R., \& Tricahyono, D. (2019). Identifikasi Faktor-Faktor Kesuksesan Start Up Digital di Kota Bandung. Jurnal Ekonomi, 27(2), 134-145.

Jaya, M. A., Ferdiana, R., \& Fauziati, S. (2017). Analisis Faktor Keberhasilan SDM Startup yang Ada di Yogyakarta. Prosiding SNATIF, 04, 175-179.

Khairil Hamdi. (2019). Pengembangan Usaha Kuliner Home Industri Sebagai Peluang Kaum Perempuan Menuju Industri Kreatif. Dinamisia : Jurnal Pengabdian Kepada Masyarakat, 3, 110116.

https://doi.org/10.31849/dinamisia.v3i 2.2867

Kim, B., Kim, H., \& Jeon, Y. (2018). Critical success factors of a design startup business. Sustainability (Switzerland), 10(9), $1-15$.

https://doi.org/10.3390/su10092981

Lutfiani, N., Rahardja, U., \& Manik, I. S. P. (2020). Peran Inkubator Bisnis dalam Membangun Startup pada Perguruan Tinggi. Jurnal Penelitan Ekonomi Dan Bisnis, 5(1), 77-89. https://doi.org/10.33633/jpeb.v5i1.272
7

Prastya Nugraha, A. E., \& Wahyuhastuti, N. (2017). Start Up Digital Business: Sebagai Solusi Penggerak Wirausaha Muda. Jurnal Nusantara Aplikasi Manajemen Bisnis, 2(1), 1. https://doi.org/10.29407/nusamba.v2i1 .701

Syauqi, A. T. (2016). Startup sebagai Digitalisasi Ekonomi dan Dampaknya bagi Ekonomi Kreatif di Indonesia. Department of Electrical Engineering and Information Technology, 1-4. 